Solmi, F; Von Wagner, C; Kobayashi, LC; Raine, R; Wardle, J; Morris, S; (2015)

Decomposing socio-economic inequality in colorectal cancer screening uptake in England.

Social Science \& Medicine, 134 pp. 76-86. Downloaded from UCL Discovery:

http://discovery.ucl.ac.uk/1467026

\title{
ARTICLE
}

\section{Decomposing socio-economic inequality in colorectal cancer screening uptake in England}

Francesca Solmia', Christian Von Wagnerb, Lindsay C. Kobayashib,Rosalind Rainea, Jane Wardleb, Stephen Morrisa

${ }^{1}$ Department of Applied Health Research, University College London

${ }^{2}$ Health Behaviour Research Centre, Department of Epidemiology and Public Health, University College London

\section{Abstract}

Colorectal cancer (CRC) is the second largest cause of cancer death in the UK. Since 2010, CRC screening based on Faecal Occult Blood testing has been offered by the NHS in England biennially to all persons age 60 to 69 years. Several studies have demonstrated a gradient in uptake using area-level markers of socio-economic status (SES), but few have examined the individual-level contributors to the gradient. We aimed to quantify the extent of SES inequality in CRC screening uptake in England using individual-level data, and to identify individual factors associated with this inequality.

We used data from 1,833 participants (aged 61-69) in Wave 5 (collected in years 2010/11) of the English Longitudinal Study of Ageing (ELSA) eligible for having been sent at least one CRC screening invitation. Uptake was defined by self-report of ever having been screened as part of the National Screening Programme. We assessed socio-economic inequality using the corrected concentration index of uptake against SES rank, which was derived by regressing a range of SES markers against net non-pension household wealth. Other demographic and health-related variables were included in the analysis. Factors associated with inequality were measured using concentration index decomposition.

There was a significant pro-rich gradient in screening uptake (concentration index: 0.16, $95 \% \mathrm{Cl}: 0.11-0.22)$, mostly explained within our model by differences in non-pension wealth $(38.7 \%)$, partner screening status $(15.9 \%)$, sickness/disability $(13.5 \%)$, and health literacy $(8.5 \%)$.

Interventions aimed at reducing inequalities in CRC screening uptake should focus on improving acceptability of screening in populations with low levels of education and literacy barriers.

Keywords: England, ELSA, colorectal cancer, screening, inequalities, health literacy, concentration

Index: decomposition analyses.

\section{Introduction}


Colorectal cancer $(\mathrm{CRC})$ is the second largest cause of cancer death in the UK $(16,000$ deaths per year) (NHS, 2013) and in 2011 was the third most common cancer in men $(23,171$ cases) and women (18,410 cases) (Cancer Research UK, 2014). Early detection through screening has been shown to be cost-effective (Tappenden et al., 2007) and effective in reducing CRC mortality (Hewitson, Glasziou, Irwig, Towler, \& Watson, 2007; Schoen et al., 2012).

In 2006, the National Health Service (NHS) in England implemented an organised CRC screening programme (the National Bowel Cancer Screening Programme; BCSP). By 2010, CRC screening had been rolled out nationally so that all people aged 60-69 were offered screening biennially, by means of a faecal occult blood test (FOBt) (Power, Miles, von Wagner, Robb, \& Wardle, 2009) mailed to each person's home. The upper age limit is currently being extended to 75 . Overall uptake is approximately $54 \%$ (von Wagner, Baio, et al., 2011), although rates are higher when several screening rounds are included (Lo et al., 2014). There is evidence of substantial variation in uptake by socio-economic status, with one study finding participation in the most deprived quintile of residential areas to be only $35 \%$, compared with $61 \%$ in the least deprived quintile (von Wagner, Baio, et al., 2011). Previous studies have also shown systematic differences in CRC screening participation between geographical regions of England, with London and the North East reporting the lowest and highest rates of screening, respectively (Logan et al., 2012; von Wagner, Baio, et al., 2011).

A number of socio-demographic, socio-economic (e.g. age, gender, ethnicity, marital status, education), and health-related (e.g. perceived health status, longstanding illnesses) characteristics have been proposed as explaining this gradient in screening participation (Gimeno Garcia, 2012; Power et al., 2009). Evidence suggests that women are more likely to participate in screening by FOBt than men (Gimeno Garcia, 2012), and that being married (Gimeno Garcia, 2012; Power et al., 2009) and having a partner who has also screened (van Jaarsveld, Miles, Edwards, \& Wardle, 2006) are associated with higher screening uptake. It has been found that among people who are eligible for screening being older (higher $>65$ ) is associated with higher likelihood of screening (Gimeno Garcia, 2012; Power et al., 2009). Differences in insurance coverage after the age of 65 (e.g. in the USA) have been suggested as explaining this increase in uptake, although this finding has been replicated in non-insurance based public health systems (e.g. Italy) (Gimeno Garcia, 2012; Power et al., 2009). In previous studies, individuals belonging to ethnic minorities have been found to be less likely to participate in screening; lower socio-economic status (SES) (indicating dimensions such as income, education and employment status) among ethnic minority groups is believed to mostly explain this finding (Gimeno Garcia, 2012; Power et al., 2009). More generally, low levels of education (Gimeno Garcia, 2012; Power et al., 2009) and more recently, factors such as limited health literacy, defined as the "capacity to obtain, process, and understand basic health information and services needed to make appropriate health decisions'(Institute of Medicine, 2004), have been found to be associated with lower participation in CRC screening (Gimeno Garcia, 2012; Kobayashi, Wardle, \& von Wagner, 2014; Power et al., 2009). Previous research also suggests that psychosocial determinants such as pessimistic expectations about future events, low levels of self-efficacy (i.e. a person's belief in their ability to succeed) and lack of social support, which are more frequent in individuals of low SES could explain its association with low CRC screening uptake(von Wagner, Good, Whitaker, \& Wardle, 2011). Finally, health status has been suggested as a factor affecting participation in CRC screening, although evidence with respect to the direction of this association is contradictory (Power et al., 2009). Some evidence points towards greater screening uptake in individuals with better health and healthier lifestyles, whereas in other studies those with poorer health and chronic conditions have higher uptake, possibly due to their greater engagement with the health sector (Power et al., 2009).

From a public policy perspective, identifying which characteristics provide the greatest contributions towards the observed inequalities in uptake of bowel cancer screening is important in order to devise programmes which are effective in increasing participation and prioritize interventions. The aim of this study was to determine the relative contribution of 
different factors to socio-economic inequalities in uptake of CRC screening using individuallevel data from the English Longitudinal Study of Ageing (ELSA), a representative sample of the English population aged $\geq 50$ years.

First, we quantified inequality using a methodology based on the concentration index (Wagstaff, Paci, \& van Doorslaer, 1991), plotting the cumulative proportion of total screening uptake in our study population ranked by a measure of SES. Second, we explored the univariate associations between a number of variables and screening uptake. Finally, we decomposed the observed inequality expressed by the $\mathrm{Cl}$ into the relative contribution of several factors using a multivariate regression model which included factors previously found to be associated with screening uptake in the univariate analysis (O'Donnell, van Doorslaer, Wagstaff, \& Lindelow, 2008).

\section{Materials and Methods}

\section{Sample}

The English Longitudinal Study of Ageing (ELSA) is a nationally-representative longitudinal cohort of individuals aged $\geq 50$ years, collecting data on health and disability, economic conditions, social participation, networks and well-being(Steptoe, Breeze, Banks, \& Nazroo, 2013). In wave one (2002/03), a core sample of participants were drawn from the 1998, 1999 and 2001 Health Surveys for England (HSE) (Mindell et al., 2012).

In this study we used cross-sectional data from core ELSA participants aged 61-69 who had a non-proxy interview at wave $5(2010 / 11)$. Proxy interviews were undertaken if the participant was physically or cognitively impaired or temporarily in care for part of or the whole duration of the survey fieldwork period (Steptoe et al., 2013). The age restriction was applied to ensure that all participants would have been sent at least one CRC screening invitation since BCSP initiation in 2006. Although it started in 2006, the BCSP did not achieve national coverage for individuals aged 60-69 until to 2010 due to it being progressive rolled out. Therefore, since Wave 5 of ELSA took place in 2010 only a small portion of individuals aged 60 and 70 or over would have been eligible for having received at least one invitation. Participation in the NHS CRC screening programme (ever taken part) was self-reported in wave 5. Analyses were limited to participants with: (i) valid 'yes/no' answer to the screening uptake question who reported undertaking the screening as part of the BCSP since 2006, and ii) complete data on net non-pension wealth and other variables used to derive the composite socio-economic status (SES) measure, and other demographic and health variables included in the analyses. Ethics approval for all the ELSA waves was obtained through the National Research and Ethics Committee.

\section{Variables}

\section{CRC screening}

Participants were asked if they had ever completed home testing kit to screen for bowel cancer (i.e. a faecal occult blood testing kit (FOBt) as flexible sigmoidoscopy (FSS) was not employed at the time of the survey). Over-reporting of cancer screening is known to occur in surveys (Johnston, Propper, \& Shields, 2009). In the case of FOBt, self-reports of participating in screening have been shown to be higher than reports contained in medical records, but this may be due to difficulties in obtaining true estimates from the latter (Madlensky, McLaughlin, \& Goel, 2003). In order to limit the extent of reporting bias, positive answers were followed up by three questions asking when (year and month) the test was done, and if it was done as part of the NHS BCSP.

\section{Socio-economic status}

We created a composite SES measure to rank individuals in the concentration index analysis. We used such a measure to be consistent with area-level studies which also use composite measures such as the Index of Multiple Deprivation to explore inequalities in uptake of CRC screening(von Wagner, Baio, et al., 2011) and colonoscopy (Morris et al., 2012). We used a generalised linear model (GLM) with gamma family distribution and log link function to regress household net non-pension wealth (divided by $1,000,000$ ) against a 
number of other socio-economic (education, occupational class, number of vehicles owned, housing tenure, household composition, economic activity) and socio-demographic (gender, age) variables. Net non-pension wealth refers to a measure of net housing wealth (i.e. value of primary house less outstanding primary housing debt) plus net non-housing wealth (net financial wealth and net physical wealth). This was used in previous ELSA analyses rather than household income to account for different wealth distributions in older ages(Bostock \& Steptoe, 2012; Kobayashi et al., 2014). The GLM model we used provided the best fit according to Akaike's Information Criterion compared with other distributional families and link functions. Our composite measure of SES was predicted net non-pension wealth based on the coefficients of the regression model. The household wealth measure was not equivalised to account for household composition; ELSA does not provide equivalised wealth measures on the grounds that "there is no commonly recognised way of adjusting wealth holdings to account for family size" (Oldfield, 2009); a similar approach has been used in other studies (Bostock \& Steptoe, 2012; Kobayashi et al., 2014; McMunn, Breeze, Goodman, Nazroo, \& Oldfield, 2005). We controlled for household size in our analyses.

\section{Other variables}

Socio-demographic variables used in the analyses were gender, ethnicity (White; nonWhite), marital status (single/never married; married once or more; separated/divorced; widowed), education (no qualification; up to degree level; degree or higher; and other/foreign), and age (recoded as nine individual year-of-age indicators in order to discriminate between those who could have received only one, or more than one screening invitation, as flexibly as possible).

We used separate SES indicators in the decomposition analysis: number of people in the household (one, two, three or four, five or more), occupational class (unemployed/other, semi-routine/routine, lower supervisor/technical, small employer, intermediate, and managerial); number of vehicles owned (i.e. cars, vans, or motorcycles; zero, one, two, three, four or more); housing tenure (owned outright, paying mortgage, renting, other [including: living rent-free, shared ownership and individuals for whom item was N/A]); economic activity (unemployed/other, retired/semi-retired; employed; self-employed; sick/disabled; looking after family) and quintiles of net non-pension wealth. We also included geographical indicators ( 9 Government Office Regions: North East, North West, Yorkshire and The Humber, East Midlands, West Midlands, East of England, London, South East, and South West) to investigate regional inequalities in the uptake of CRC screening.

We also included self-reported general health (poor, fair, good, very good, excellent) and long-standing limiting illness (no, yes not limiting, yes limiting) as well as a binary (yes/no) question indicating any limitation in instrumental activities of daily living (the presence of difficulties with one or more of the following activities: dressing, walking across a room, taking bath, eating, getting out of bed, or taking medications) with the sum of limitations as the variable for analysis(Kobayashi et al., 2014). A separate binary variable was used to measure any difficulties with using the toilet.

A measure of health literacy was also used in the analyses. Participants were asked to read the leaflet of a fictitious medicine and to answer 4 reading comprehension questions on its contents. Four correct answers and at least one error defined adequate and limited health literacy, respectively (Bostock \& Steptoe, 2012; Kobayashi et al., 2014). A variable indicating difficulties in comprehending English was not included in this study since these were reported only by $0.5 \%$ of the sample.

Finally, we included a variable indicating whether the participant had a partner who they lived with who also screened for CRC. To derive this variable we counted the number participants in our dataset (i.e. those people who were eligible for CRC screening), living in each household; in the dataset there were either 1 or 2 . Because of the age restriction applied to our sample, if a household had one eligible participant it could mean either that the participant did not have a partner or that they had a younger (i.e. ineligible) partner. These participants were grouped together in the analyses. In the case of households with 
two eligible CRC screening participants if both participants had screened for CRC, they were both coded as having a partner who screened; if both partners were eligible for screening on the basis of their age but only one participant had screened the one who had screened was coded as having a partner who did not screen and the one who did not screen as having a partner who screened. The final version of this variable had three categories accounting for whether the participants: (1) had a partner who was eligible for screening and had been screened for CRC, (2) had a partner who was not screened despite being age-eligible, or (3) did not have a partner or had a partner who was not eligible.

\section{Statistical analyses}

Cross-sectional survey weights for wave 5 accounting for varying propensities to respond among key subgroups and the clustering of the data at household level were applied in all analyses. We assessed socio-demographic, socio-economic and health differences between individuals who did and did not screen for CRC using $x^{2}$ tests (for categorical variables) and one-way ANOVA (continuous variables).

Variables included in the concentration index decomposition were selected after fitting univariate probit models for the association between the socio-demographic, socioeconomic, and health-related variables and the probability of screening. Variables with any categories that were significantly associated with uptake of screening in univariate models were retained in multivariate models. For both univariate and multivariate models, marginal effects of the change in probability of CRC screening for a unit change in the predictor variables were reported.

\section{Measuring socio-economic inequality}

Socio-economic inequalities in uptake of CRC screening were visually inspected with a concentration curve, quantified with the concentration index and subsequently decomposed into associated factors using decomposition analysis. The concentration curve plots the cumulative proportion of the investigated outcome (y-axis) against the cumulative proportion of the population ranked by a measure of income or SES (x-axis) (O'Donnell et al., 2008). The 45 degree line represents perfect equality; if the curve lies below or above the line, the outcome is more concentrated among the higher or lower SES individuals in the population, respectively.

The concentration index is twice the area between the concentration curve and the line of perfect equality. It is calculated as twice the weighted covariance between the outcome (in our case $\mathrm{CRC}$ screening uptake) and the fractional rank in the wealth distribution divided by the variable mean(O'Donnell et al., 2008):

$$
C I=\frac{2}{\mu} \operatorname{cov}_{w}\left(h_{i} r_{i}\right)
$$

where $\mathrm{Cl}$ is the concentration index; $h$ is CRC screening uptake; $r$ is the fractional rank of the individual $i$ in terms of wealth (SES) distribution; $\mu$ is the weighted mean value of the CRC screening uptake variable; and, $\operatorname{cov}_{w}$ is the weighted covariance (O'Donnell et al., 2008). Its value can range between -1 and 1 , with 0 , negative values and positive values representing perfect equality, pro-poor inequality and pro-rich inequality, respectively.

It has been argued that using the $\mathrm{Cl}$ with binary outcome variables has several limitations, such as, for instance: that its bounds could vary across populations with different mean values of the outcome variable limiting the scope for inter-group comparisons; that the range of possible values that the $\mathrm{Cl}$ could assume are not limited between -1 and +1 ; and, finally, that it does not satisfy the 'mirror' condition (i.e. inequalities in ill-health do not 'mirror' those of good health) (Costa-Font, Hernández-Quevedo, \& Jiménez-Rubio, 2014). Wagstaff (2005) and Erreygers (2009) have proposed different correction mechanisms to deal with these problems, the former measuring relative inequalities, the latter quasi-absolute inequalities. Given its focus on quasi-absolute inequalities we use the Erreygers (2009) correction, which has also been used in other studies (Costa-Font et al., 2014; VallejoTorres \& Morris, 2010), and is given by: 
(2) $E_{C I}=\frac{4 \mu}{h_{\max }-h_{\min }} C I$

Where $\mu$ is the mean value of the health variable, $h_{\max }$ and $h_{\min }$ represent its bounds, and $\mathrm{Cl}$ is the standard concentration index. Following others (Costa-Font et al., 2014; Vallejo-Torres \& Morris, 2010) we will refer to this index as the corrected concentration index (CCl).

As shown by Wagstaff et al (Wagstaff, van Doorslaer, \& Watanabe, 2003) the concentration index can be conceptualised as the sum of the contribution to inequality of a number of factors, such as socio-economic, socio-demographic, geographical, and policy indicators (the 'deterministic' or explained component), as well as an unexplained residual component. The original decomposition method assumes an underlying Ordinary Least Squares (OLS) regression model (Wagstaff et al., 2003); however, decomposition analyses can be undertaken with dichotomous outcomes if based on a linear approximation of the model (O’Donnell et al., 2008; Yiengprugsawan, Lim, Carmichael, Dear, \& Sleigh, 2010; Yiengprugsawan, Lim, Carmichael, Sidorenko, \& Sleigh, 2007). We used marginal effects derived from a probit model to produce an additive/linear approximation of the model, as expressed by the formula:

$$
y_{i}=\alpha+\sum_{k} \beta_{k i}+u_{i}
$$

Where $\beta_{k}$ is the marginal effect of variable $x$ calculated at the sample mean value, and $u$ is the residual error term. The concentration index can be rewritten as:

$$
C I=\sum_{k}\left(\frac{\beta_{k} \bar{x}_{k}}{\mu}\right) C I_{k} \frac{G C I_{u}}{\mu}
$$

where $\mu$ is the weighted mean value of the outcome (screening uptake); $\bar{x}_{k}$ is the mean of $x_{k}$ and $C I_{k}$ is the concentration index of each determinant $x_{k}$ against SES rank ${ }^{19,20} . \mathrm{GCl}_{u}$ is a generalised concentration index for ${ }^{19}$. For each of the $k x$ variables we also calculate their elasticity

$\eta_{k}=\left(\frac{\beta_{k} \bar{x}_{k}}{\mu}\right)$, and their contribution $\left(Q_{k}=\eta_{k} C I_{k}\right)$ and percentage contribution $\left(100 Q_{k} / C I\right)$ to overall observed socio-economic inequality. We used bootstrapping to derive standard errors (SEs) for the contribution of each variable. We ran 1000 replications of Eq.s $(1,3,4)$.

As shown in Eq.(3), the contribution of each determinant $x_{k}$ to the concentration index is a function of both the effect on the outcome $\left(\beta_{k} \bar{x}_{k} / \mu\right)$ and of the extent of the inequality in its distribution across wealthy and non-wealthy participants $\left(C I_{k}\right)$. This means that if the marginal effect of a factor is large, but no inequalities exist in the distribution of that factor then its contribution to overall inequality will be low. Conversely, if a factor is concentrated amongst participants differentiated by their SES and the marginal effect of the factor is large then its contribution to the overall concentration index will be large (Yiengprugsawan et al., 2007).

\section{Results}

Sample

Of 8,741 core ELSA participants with non-proxy interviews who took part in wave 5, 3,071 were aged 61 to 69 and 1,930 had answered the questions regarding participation in CRC screening. Of those who took the test, $2.3 \%(\mathrm{~N}=28)$ said they had not screened as part of the BCSP and $0.2 \%(\mathrm{~N}=2)$ that they did not know if they were screened as part of the BCSP or not. Of those who reported taking part in the BCSP, $5(0.4 \%)$ said they had done so prior to 2006 (i.e. before the start of the programme) and $5(0.4 \%)$ did not know when they did it. We compared these 40 participants (3.3\%) against those who had undergone CRC screening through the NHS programme on all socio-demographic, socio-economic and health variables included in the analyses using $x^{2}$ tests. There were no differences in socioeconomic or socio-demographic characteristics; but a higher proportion of participants who had not been screened as part of the national programme had a longstanding illness. Since this group was systematically different from the main sample, and the differences may affect 
screening uptake (their illness may have made them eligible for screening outside the BCSP), they were dropped from the analyses (Figure S1, available in appendix) leaving 1,890 participants with a valid answer to the question on CRC screening. After excluding cases with missing data on income $(\mathrm{N}=54,2.9 \%)$, education, $(\mathrm{N}=1,0.05 \%)$, marital status $(\mathrm{N}=1,0.05 \%)$ and occupational class $(\mathrm{N}=1,0.05 \%)$ a total of 1,833 participants were retained in the final sample (Figure S1, available in appendix). The sample does not contain any residents of care homes or nursing homes. There were 70 participants in ELSA wave 5 who were resident in an institution, only 2 answered the questions about CRC screening participation and these were dropped from the sample after applying the other criteria described above.

Just over half of the sample were women (55.4\%) and the majority had secondary education or higher $(68.9 \%)$, were married $(76.1 \%)$, and were retired or semi-retired $(72.3 \%)$. There were no differences in age, gender, screening uptake, or economic activity between participants with complete data and those missing data on non-pension wealth and other covariates.

\section{Predicted SES measure}

Results of the net non-pension wealth regressions are in Table 3. Net non-pension wealth is positively correlated with age, education, occupational class, number of vehicles owned and house ownership. The rank order correlation of the predicted SES variable (mean: 0.40, SD: 0.31 ; range: $0.006-2.735$ ) and the original wealth variable was 0.68 .

\section{Univariate analysis}

Overall, the rate of screening uptake (ever taken part in the CRC screening programme) was $61.0 \%$ (Table $1 \& 2$ ). Uptake was significantly higher among women, and those of White ethnicity, educated to degree level or above, married (or living as married), in intermediate or managerial roles, who owned more vehicles and a house, were retired, and who were in the top four wealth quintiles and those who lived in the North East, East of England, East Midlands, West Midlands and Yorkshire \& The Humber. Uptake of CRC screening was highest in the North East across all wealth quintiles (figure S2, available in appendix). Uptake was also higher in those with 'excellent' self-reported health, with no longstanding illnesses, and an adequate health literacy level. In addition, uptake was higher among those who had a partner who had been screened. No differences in screening uptake existed between participants who had difficulties in either using the toilet or daily activities and those who did not have difficulties and between participants of different ages.

\section{Multivariate analysis SES}

In the multivariate model (Table 4 'Multivariate marginal effects' column), only gender, health literacy, partner screening status, economic activity, and housing tenure, and region were significantly associated (i.e. joint variable significance) with screening uptake. Individuals who had an eligible partner who did not participate in screening, who were sick or disabled, as well as those who were paying a mortgage, had a lower probability of screening compared to those without a (eligible) partner, who were in employment or owned their home. Women and individuals with a partner eligible for screening who also screened had a higher probability of screening compared to men and participants without a (eligible) partner. Finally, participants with limited health literacy were less likely to participate in screening compared to those with adequate levels of health literacy. There was some evidence of regional variation in uptake of screening controlling for the other variables in the multivariate model; the probability of screening was lower in the North West, London, South East and South West.

\section{Concentration index}

The corrected concentration index of screening uptake against SES rank was $0.16(95 \% \mathrm{Cl}$ : 0.11 to $0.22, p<0.0001$ ) suggesting statistically significant pro-rich inequalities in uptake of $\mathrm{CRC}$ screening; this inequality in uptake is reflected by the concentration curve (Fig. 1). Subgroup analyses suggested that inequalities were higher among men, participants with no education, and those who were: single; either lived alone or in households with more than 5 
people; had low self-reported levels of health, limited health literacy; difficulties with daily activities; and were unemployed or disabled (Table S1, available in appendix)

\section{Decomposition analyses}

All variables included in the multivariate model were included in the decomposition analyses Among the variables where the categories were jointly significant, those with the greatest contributions towards inequality in screening were: non-pension wealth $(38.7 \%, 0.05<p \leq 0.1)$, health literacy $(8.5 \%, p<0.05)$, and partner screening status $(16 \%, p<0.05)$ (Table 4$)$. Individual characteristics that contributed towards increased inequality were: belonging to the poorest quintile of net non-pension wealth $(34 \%, 0.05<\mathrm{p} \leq 0.1)$, being sick or disabled $(13.5 \%, p<0.05)$, having a partner who was also screened $(15.8 \%, p<0.05)$ and a low (fair) level of self-reported general health $(10.6 \%, 0.05<p \leq 0.1)$. Being sick and disabled, having a fair level of self-reported general health and being in the poorest wealth quintile had a negative association with CRC screening, indicated by a negative elasticity, and were also concentrated among the less wealthy participants; hence, their contribution to inequality was high. On the other hand, having a partner who also screened was characterised by a positive elasticity and was concentrated among wealthier participants, also providing a large contribution towards inequalities. We reran the decomposition analyses based on the coefficients of a linear probability model instead of the marginal effects from a probit model and obtained comparable results (Table S2, available in appendix).

\section{Discussion}

\section{Summary}

The aim of this study was to investigate the relative contribution of factors associated with individual-level socio-economic inequalities in CRC screening participation in a representative sample of the English population within the screening age-range. Uptake of screening was higher in our sample $(61.0 \%)$ than in other studies (von Wagner, Baio, et al., 2011), probably because the age profile meant that the older participants were likely to have been invited over two or more rounds which, as reported recently, can increase uptake (Lo et al., 2014). A recent study using ELSA data, but including a broader age range, found a $57 \%$ uptake of screening (Gale, Deary, Wardle, Zaninotto, \& Batty, 2015). Consistent with a previous study (von Wagner, Baio, et al., 2011), we found a strong gradient in uptake with $41.7 \%$ of individuals in the poorest and $65.5 \%$ in the richest quintiles of predicted nonpension wealth participating in screening. Our findings are also consistent with international studies showing the existence of a gradient in CRC screening regardless of broader system factors (e.g. insurance-based health systems) (O'Donnell et al., 2008). Making use of rich individual level data, our analyses showed the existence of pro-rich inequalities (CCl: 0.16$)$ in screening uptake with respect to wealth, health literacy region and partner screening status. Despite the scarcity of directly comparable studies using this measure in the UK, our figure appears similar to those of other European countries for uptake of colonoscopy or stool examination, such as Belgium ( $\mathrm{CCl} 0.04)$, Germany (CCl: 0.126), France 0.135 (but not Denmark, CCl:-0.074) (Carrieri \& Wuebker, 2013) and Ireland (Cl: 0.069) (Walsh, Silles, \& O'Neill, 2012), although the latter estimate did not employ the Erreygers correction (Erreygers, 2009).

If all people who are eligible for bowel cancer screening are in equal need of it then inequality in uptake as found in this study could also be recognised as horizontal inequity in uptake (i.e., unequal treatment of those in equal need). Hence, pro-wealthy inequality might also be described as pro-wealthy horizontal inequity.

Disparities in SES have consistently been identified as factors driving different patterns of CRC screening uptake(Gimeno Garcia, 2012; Power et al., 2009). Of the several dimensions captured by the concept of SES, low income has been associated with lower levels of CRC screening in both public and private healthcare systems and in both organized and opportunistic screening systems (Gimeno Garcia, 2012; Liang, Phillips, Nagamine, Ladabaum, \& Haas, 2006; Seeff et al., 2004; von Wagner, Baio, et al., 2011; Walsh et al., 2012). In our study, once we controlled for a number of socio-demographic, socio-economic and health variables, we found evidence of an independent association between limited 
wealth and lower probability of screening or inequality in screening. This suggests that the apparent pro-rich pattern in screening uptake could be mediated by a number of factors associated with wealth, which we have not measured in our analyses. As we previously reported, it has been speculated that a number of psychosocial factors might mediate the association between low income and screening uptake (von Wagner, Good, et al., 2011).

Education, central to the construct of SES, has previously been associated with screening participation (Gimeno Garcia, 2012; Power et al., 2009), and we found that it explained $18.6 \%$ of the inequality in our sample. However, its individual contribution was not significant in the decomposition analysis, nor was its association with screening status significant in multivariate analyses. Health literacy is associated with educational attainment, and may have partly mediated the contribution of education to screening inequality in the decomposition analysis. As a measure of current functional skills, health literacy has predictive capability over and above education for health outcomes including colorectal cancer screening (Kobayashi et al., 2014). It has been suggested that low health literacy results in poorer health outcomes through differential processes of access to care, patientprovider interactions, and self-care (von Wagner, Steptoe, Wolf, \& Wardle, 2009). Low health literacy is postulated to result in lower screening attendance through causing limited knowledge of health services and diseases, difficulty in understanding abstract concepts such as risk, a preference for emotional over factual information, and lower decision-making skills(von Wagner, Steptoe, et al., 2009). In the context of CRC screening, previous studies have shown that individuals with low levels of health literacy report more problems in seeking and processing health-related information (von Wagner, Semmler, Good, \& Wardle, 2009), as well as barriers in understanding (Arnold et al., 2012; Peterson, Dwyer, Mulvaney, Dietrich, \& Rothman, 2007) or completing screening(Kobayashi et al., 2014). In line with these hypotheses, we found that inadequate health literacy was associated with lower probability of screening uptake in univariate and multivariate models, and it contributed to nearly $8 \%$ of inequality. Future work should investigate the pathways through which low health literacy influences the uptake of colorectal cancer screening.

We did not find differences in uptake of screening by age. Higher uptake in older individuals has been documented in the literature (Gimeno Garcia, 2012; Power et al., 2009); with the underlying causal mechanism hypothesised as greater engagement with the health sector due to declining health (von Wagner, Baio, et al., 2011). However, we found that uptake of screening was higher in participants with better self-reported general health and no longstanding illnesses, although the latter only in univariate models. Because poorer health was concentrated in participants with lower SES, self-reported general health had a high contribution to health inequalities in CRC screening uptake in our sample $(10.6 \%$ $0.1>p>0.05$ ). Factors such as fatalistic attitudes towards cancer, previous experiences of illhealth, and distrust in the medical system, which are more common in individuals with both poorer health and low SES, have been shown to mediate the association between poor health and lower uptake of CRC screening (von Wagner, Good, et al., 2011). Being sick/disabled was independently associated with lower screening uptake in multivariate models, and contributed to $14 \%$ of inequality in uptake of screening, suggesting the plausibility of this hypothesis in our sample.

In contrast with previous studies (Gimeno Garcia, 2012; Power et al., 2009) we did not find lower uptake of CRC screening in participants of non-White ethnic background in multivariate analyses, although under-representation of ethnic minorities in our sample may have limited the statistical power of our analyses resulting in a type II error. It is also possible that owing to the richness of the ELSA dataset, we were able to include a range of covariates that previous studies were unable not accounted for, such as health literacy that could be mediators for non-participation among non-White groups. More research including ethnically diverse samples is warranted to ensure representativeness and generalizability of results. We also found that women had a higher probability of screening than men, which echoes the findings of previous studies on FOBt screening (Gimeno Garcia, 2012). 
In all analyses, we observed a higher probability of participating in screening among individuals belonging to couples where the partner had been screened. Similarly, previous studies found higher odds of screening attendance when both partners were invited to screen at the same time (van Jaarsveld et al., 2006). However, as in previous studies (van Jaarsveld et al., 2006), we did not have information on communication between partners, which could partially mediate this association. Further research elucidating how partner communication dynamics affect screening attendance is warranted. Having a partner who screened, more frequent among wealthier participants, significantly accounted for a large portion $(17 \%)$ of inequality in screening attendance. However, because the partner data were inevitably clustered in the dataset, future analyses are needed that decompose the partner effect and identify whether it is due to shared environmental characteristics or a genuine influence on participation.

Finally, in agreement with previous findings at different stages of BCSP implementation (Logan et al., 2012; von Wagner, Baio, et al., 2011), we found significant regional differences in CRC uptake. Uptake was highest in the North East across all wealth quintiles and lowest in London, although in multivariate regression models we did not see significant differences between London, the South East, the South West, and the North West. Although it is not clear why uptake of CRC screening appears to vary between regions, especially with respect to London it has been argued that lower uptake could be due to a more varied population, both from a socio-economic and socio-demographic viewpoint. In our analyses we were able to adjust for a number of these hypothesised factors (e.g. income, ethnicity) and the regional differences persisted. It is possible that structural factors (e.g. lost mail and thus inefficiencies in the invitation system) not specific to CRC screening could affect screening participation in this areas, as it has previously speculated and future studies could investigate these observed differences further.

\section{Strengths and limitations}

This study has several strengths. It is one of the first UK studies to have rich individual-level data, allowing us to assess the importance of a wide range of individual factors simultaneously in multivariate models. Moreover, we applied decomposition analyses to the study of inequalities in CRC screening uptake, which to the best of our knowledge has only previously been used to investigate the uptake of CRC screening in Ireland with a focus on the role of having access to private insurance and uptake of colonoscopy or stool examination in a number of European countries (Carrieri \& Wuebker, 2013; Walsh et al., 2012) This method has allowed us to expand on previous findings by quantifying the extent of socio-economic inequality attached to each hypothesised determinant.

Some important limitations should be noted. Most importantly, screening uptake was selfreported and we did not have any objective verification. It is possible that participation was over-reported due to confusion with other cancer screening programmes or other clinical investigations of bowel symptoms. However, self-report of CRC screening has been found to be accurate (Madlensky et al., 2003). We excluded all individuals who might have not received an invitation to screen based on their age at initiation of the programme in order to avoid overestimating the presence of inequalities in screening uptake. In doing so, however, we might have excluded participants who received an invitation to screen and did not respond. Our analyses could suffer from some degree of attrition as individuals with missing values on non-pension wealth and some outcomes were dropped from the analyses. We compared individuals with complete data against those with any missingness on income and socio-demographic, socio-economic and health-related correlates (i.e. age, gender, marital status, education, self-reported general health, longstanding limiting illness, and occupational class) and did not find any systematic differences in observed data. Non-White ethnicity was under-represented in our sample, thus not allowing for further investigation of socio-economic inequalities typical of these groups. Although net non-pension wealth has been indicated as a better measure of socioeconomic status than income for people of this age range (Bostock \& Steptoe, 2012), there is no commonly recognised method to adjust household wealth to account for household composition (Oldfield, 2009). Therefore our socioeconomic status measure is not adjusted for household composition. Finally, the total 
percentage contribution of our decomposition model only explained $97.2 \%$ of the inequality. This could be due to residual, unmeasured factors, but also because of the linear approximation derived from marginal effects explained in Eq.s (2) and (3). When we reran the model using a linear functional form the results were qualitatively similar. Our dataset does not include people living in care homes and nursing homes, and their uptake of CRC screening and the factors associated with that uptake may be different from those living in their own homes. Without further evidence it is not appropriate to generalize our findings to people living in institutions; further research among these groups would be beneficial. 


\section{Implications}

Based on our results, policies and programmes aimed at reducing the gradient in CRC participation should devise strategies to increase acceptability and comprehension of the screening test among those with lower levels of literacy. Although more evidence supporting the efficacy of patient navigation models (Freeman \& Rodriguez, 2011; Paskett, Harrop, \& Wells, 2011) is needed, in the context of CRC screening telephone support provided by a registered nurse or a medical assistant with understanding cancer risk and screening procedure as well as with following up screening completion, has been shown to be a successful strategy in increasing screening uptake(Green et al., 2013). More research is warranted to explore how successful these interventions could be in reducing the gradient in screening participation. Effective interventions should also emphasise the social implications of screening and its benefit not just to the individual but their family and friends. Interventions at the individual level, which have shown to modify and improve negative perceptions and attitudes to screening in harder-to-reach individuals include the use of psycho-educational material as an alternative to regular screening invitations (Wardle et al., 2003) as well as enhanced reminders. Since some evidence also exists on the effectiveness of small media and group educational interventions in increasing uptake of CRC screening future studies should aim to integrate different approaches to investigate the extent of their effect in reducing the social gradient in uptake(Baron et al., 2008).

\section{Conclusion}

In conclusion, we found a strong socio-economic gradient in uptake of CRC. Low educational attainment and inadequate health literacy were found to be significantly associated with lower uptake of screening, as well as making large contributions to inequalities. Future research could focus on identifying the screening offer delivery methods that most effectively reduce inequalities in uptake and prevent the emergence of greater inequalities in CRC deaths.

Appendix: Supplementary data

The following appendix contains the supplementary data related to this article: 


\section{RESEARCH HIGHLIGHTS}

- We found a significant SES gradient in the uptake of CRC screening in ELSA.

- Education and health literacy made large contributions to inequalities in screening uptake.

- Participants who were sick or disabled had lower probability to screen and were affected by a high degree of inequality.

- Having a partner who screened was strongly associated with screening uptake.

- Interventions to reduce inequalities in uptake should aim to improve screening acceptability in groups with poor health literacy. 


\section{REFERENCES}

Arnold, C. L., Rademaker, A., Bailey, S. C., Esparza, J. M., Reynolds, C., Liu, D., ... Davis, T. C. (2012). Literacy barriers to colorectal cancer screening in community clinics. Journal of Health Communication, 17 Suppl 3, 252-64. doi:10.1080/10810730.2012.713441

Baron, R. C., Rimer, B. K., Breslow, R. A., Coates, R. J., Kerner, J., Melillo, S., ... Briss, P. A. (2008). Client-directed interventions to increase community demand for breast, cervical, and colorectal cancer screening a systematic review. American Journal of Preventive Medicine, 35(1 Suppl), S34-55. doi:10.1016/j.amepre.2008.04.002

Bostock, S., \& Steptoe, A. (2012). Association between low functional health literacy and mortality in older adults: longitudinal cohort study. BMJ (Clinical Research Ed.), 344(mar15_3), e1602. doi:10.1136/bmj.e1602

Cancer Research UK. (2014). Bowel Cancer Statistics. Retrieved February 26, 2014, from http://www.cancerresearchuk.org/cancer-info/cancerstats/types/bowel/incidence/

Carrieri, V., \& Wuebker, A. (2013). Assessing inequalities in preventive care use in Europe. Health Policy, 113(3), 247-257. doi:10.1016/j.healthpol.2013.09.014

Costa-Font, J., Hernández-Quevedo, C., \& Jiménez-Rubio, D. (2014). Income inequalities in unhealthy life styles in England and Spain. Economics and Human Biology, 13, 66-75. doi:10.1016/j.ehb.2013.03.003

Erreygers, G. (2009). Correcting the concentration index. Journal of Health Economics, 28(2), 504-15. doi:10.1016/j.jhealeco.2008.02.003

Freeman, H. P., \& Rodriguez, R. L. (2011). History and principles of patient navigation. Cancer, 117(15 Suppl), 3539-42. doi:10.1002/cncr.26262

Gale, C. R., Deary, I. J., Wardle, J., Zaninotto, P., \& Batty, G. D. (2015). Cognitive ability and personality as predictors of participation in a national colorectal cancer screening programme: the English Longitudinal Study of Ageing. Journal of Epidemiology and Community Health, jech-2014-204888-. doi:10.1136/jech-2014-204888

Gimeno Garcia, A. Z. (2012). Factors Influencing Colorectal Cancer Screening Participation. Gastroenterology Research and Practice. doi:dx.doi.org/10.1155/2012/483417

Green, B. B., Wang, C.-Y., Anderson, M. L., Chubak, J., Meenan, R. T., Vernon, S. W., \& Fuller, S. (2013). An automated intervention with stepped increases in support to increase uptake of colorectal cancer screening: a randomized trial. Annals of Internal Medicine, 158(5 Pt 1), 301-11. doi:10.7326/0003-4819-158-5-201303050-00002

Hewitson, P., Glasziou, P., Irwig, L., Towler, B., \& Watson, E. (2007). Screening for colorectal cancer using the faecal occult blood test, Hemoccult. The Cochrane Database of Systematic Reviews, (1), CD001216. doi:10.1002/14651858.CD001216.pub2

Institute of Medicine. (2004). Health Literacy: A Prescription to End Confusion. Washington, D.C.: The National Academies Press.

Johnston, D. W., Propper, C., \& Shields, M. A. (2009). Comparing subjective and objective measures of health: Evidence from hypertension for the income/health gradient. Journal of Health Economics, 28(3), 540-52. doi:10.1016/j.jhealeco.2009.02.010

Kobayashi, L. C., Wardle, J., \& von Wagner, C. (2014). Limited health literacy is a barrier to colorectal cancer screening in England: Evidence from the English Longitudinal Study of Ageing. Preventive Medicine, 61(100), 100-105. doi:10.1016/j.ypmed.2013.11.012

Liang, S.-Y., Phillips, K. A., Nagamine, M., Ladabaum, U., \& Haas, J. S. (2006). Rates and Predictors of Colorectal Cancer Screening. Centers for Disease Control and Prevention. Retrieved from http://dash.harvard.edu/handle/1/5129836 
Lo, S. H., Halloran, S., Snowball, J., Seaman, H., Wardle, J., \& von Wagner, C. (2014). Colorectal cancer screening uptake over three biennial invitation rounds in the English bowel cancer screening programme. Gut, gutjnl-2013-306144-. doi:10.1136/gutjnl2013-306144

Logan, R. F. A., Patnick, J., Nickerson, C., Coleman, L., Rutter, M. D., \& von Wagner, C. (2012). Outcomes of the Bowel Cancer Screening Programme (BCSP) in England after the first 1 million tests. Gut, 61(10), 1439-46. doi:10.1136/gutjnl-2011-300843

Madlensky, L., McLaughlin, J., \& Goel, V. (2003). A Comparison of Self-reported Colorectal Cancer Screening with Medical Records. Cancer Epidemiol. Biomarkers Prev., 12(7), 656-659. Retrieved from http://cebp.aacrjournals.org/content/12/7/656.long

McMunn, A., Breeze, E., Goodman, A., Nazroo, J., \& Oldfield, Z. (2005). Social Determinants of Health in Older Age. In M. Marmot \& R. Wilkinsgon (Eds.), Social Determinants of Health (2nd ed.). Oxford: Oxford University Press.

Mindell, J., Biddulph, J. P., Hirani, V., Stamatakis, E., Craig, R., Nunn, S., \& Shelton, N. (2012). Cohort profile: the health survey for England. International Journal of Epidemiology, 41(6), 1585-93. doi:10.1093/ije/dyr199

Morris, S., Baio, G., Kendall, E., von Wagner, C., Wardle, J., Atkin, W., ... Raine, R. (2012). Socioeconomic variation in uptake of colonoscopy following a positive faecal occult blood test result: a retrospective analysis of the NHS Bowel Cancer Screening Programme. British Journal of Cancer, 107(5), 765-71. doi:10.1038/bjc.2012.303

NHS. (2013). NHS Bowel Cancer Screening Programme. Retrieved April 02, 2014, from http://www.cancerscreening.nhs.uk/bowel/

O'Donnell, O., van Doorslaer, E., Wagstaff, A., \& Lindelow, M. (2008). Analyzing Health Equity Using Household Survey Data. World Bank Publications. Retrieved from http://siteresources.worldbank.org/INTPAH/Resources/Publications/4598431195594469249/HealthEquityFINAL.pdf

Oldfield, Z. (2009). Financial derived variables ELSA Waves 1-4. UK Data Archive.

Paskett, E. D., Harrop, J. P., \& Wells, K. J. (2011). Patient navigation: an update on the state of the science. CA: A Cancer Journal for Clinicians, 61(4), 237-49. doi:10.3322/caac.20111

Peterson, N. B., Dwyer, K. A., Mulvaney, S. A., Dietrich, M. S., \& Rothman, R. L. (2007). The influence of health literacy on colorectal cancer screening knowledge, beliefs and behavior. Journal of the National Medical Association, 99(10), 1105-12. Retrieved from http://www.pubmedcentral.nih.gov/articlerender.fcgi?artid=2574401\&tool=pmcentrez\&re ndertype $=$ abstract

Power, E., Miles, A., von Wagner, C., Robb, K., \& Wardle, J. (2009). Uptake of colorectal cancer screening: system, provider and individual factors and strategies to improve participation. Future Oncology (London, England), 5(9), 1371-88. doi:10.2217/fon.09.134

Schoen, R. E., Pinsky, P. F., Weissfeld, J. L., Yokochi, L. A., Church, T., Laiyemo, A. O., ... Berg, C. D. (2012). Colorectal-cancer incidence and mortality with screening flexible sigmoidoscopy. The New England Journal of Medicine, 366(25), 2345-57. doi:10.1056/NEJMoa1114635

Seeff, L. C., Nadel, M. R., Klabunde, C. N., Thompson, T., Shapiro, J. A., Vernon, S. W., \& Coates, R. J. (2004). Patterns and predictors of colorectal cancer test use in the adult U.S. population. Cancer, 100(10), 2093-103. doi:10.1002/cncr.20276

Steptoe, A., Breeze, E., Banks, J., \& Nazroo, J. (2013). Cohort profile: the English Longitudinal Study of Ageing. International Journal of Epidemiology, 42(6), 1640-8. doi:10.1093/ije/dys168 
Tappenden, P., Chilcott, J., Eggington, S., Patnick, J., Sakai, H., \& Karnon, J. (2007). Option appraisal of population-based colorectal cancer screening programmes in England. Gut, 56(5), 677-84. doi:10.1136/gut.2006.095109

Vallejo-Torres, L., \& Morris, S. (2010). The contribution of smoking and obesity to incomerelated inequalities in health in England. Social Science \& Medicine (1982), 71(6), 1189-98. doi:10.1016/j.socscimed.2010.06.008

Van Jaarsveld, C. H. M., Miles, A., Edwards, R., \& Wardle, J. (2006). Marriage and cancer prevention: does marital status and inviting both spouses together influence colorectal cancer screening participation? Journal of Medical Screening, 13(4), 172-6. Retrieved from http://www.ncbi.nlm.nih.gov/pubmed/17217605

Von Wagner, C., Baio, G., Raine, R., Snowball, J., Morris, S., Atkin, W., ... Wardle, J. (2011). Inequalities in participation in an organized national colorectal cancer screening programme: results from the first 2.6 million invitations in England. International Journal of Epidemiology, 40(3), 712-8. doi:10.1093/ije/dyr008

Von Wagner, C., Good, A., Whitaker, K. L., \& Wardle, J. (2011). Psychosocial Determinants of Socioeconomic Inequalities in Cancer Screening Participation: A Conceptual Framework. Epidemiologic Reviews, 33(1), 135-147. doi:10.1093/epirev/mxq018

Von Wagner, C., Semmler, C., Good, A., \& Wardle, J. (2009). Health literacy and selfefficacy for participating in colorectal cancer screening: The role of information processing. Patient Education and Counseling, 75(3), 352-7. doi:10.1016/j.pec.2009.03.015

Von Wagner, C., Steptoe, A., Wolf, M. S., \& Wardle, J. (2009). Health literacy and health actions: a review and a framework from health psychology. Health Education \& Behavior $\square$ : The Official Publication of the Society for Public Health Education, 36(5), 860-77. doi:10.1177/1090198108322819

Wagstaff, A. (2005). The bounds of the concentration index when the variable of interest is binary, with an application to immunization inequality. Health Economics, 14(4), 42932. doi:10.1002/hec.953

Wagstaff, A., Paci, P., \& van Doorslaer, E. (1991). On the measurement of inequalities in health. Social Science \& Medicine (1982), 33(5), 545-57. Retrieved from http://www.ncbi.nlm.nih.gov/pubmed/1962226

Wagstaff, A., van Doorslaer, E., \& Watanabe, N. (2003). On decomposing the causes of health sector inequalities with an application to malnutrition inequalities in Vietnam. Journal of Econometrics, 112(1), 207-223. doi:10.1016/S0304-4076(02)00161-6

Walsh, B., Silles, M., \& O'Neill, C. (2012). The role of private medical insurance in socioeconomic inequalities in cancer screening uptake in Ireland. Health Economics, 21(10), 1250-6. doi:10.1002/hec.1784

Wardle, J., Williamson, S., McCaffery, K., Sutton, S., Taylor, T., Edwards, R., \& Atkin, W. (2003). Increasing attendance at colorectal cancer screening: Testing the efficacy of a mailed, psychoeducational intervention in a community sample of older adults. Health Psychology, 22(1), 99-105.

Yiengprugsawan, V., Lim, L. L., Carmichael, G. A., Dear, K. B., \& Sleigh, A. C. (2010). Decomposing socioeconomic inequality for binary health outcomes: an improved estimation that does not vary by choice of reference group. BMC Research Notes, 3(1), 57. doi:10.1186/1756-0500-3-57

Yiengprugsawan, V., Lim, L. L., Carmichael, G. A., Sidorenko, A., \& Sleigh, A. C. (2007). Measuring and decomposing inequity in self-reported morbidity and self-assessed 
health in Thailand. International Journal for Equity in Health, 6(1), 23. doi:10.1186/1475-9276-6-23 
Tables and Figures

Figure 1: Concentration curve of CRC screening uptake against SES rank

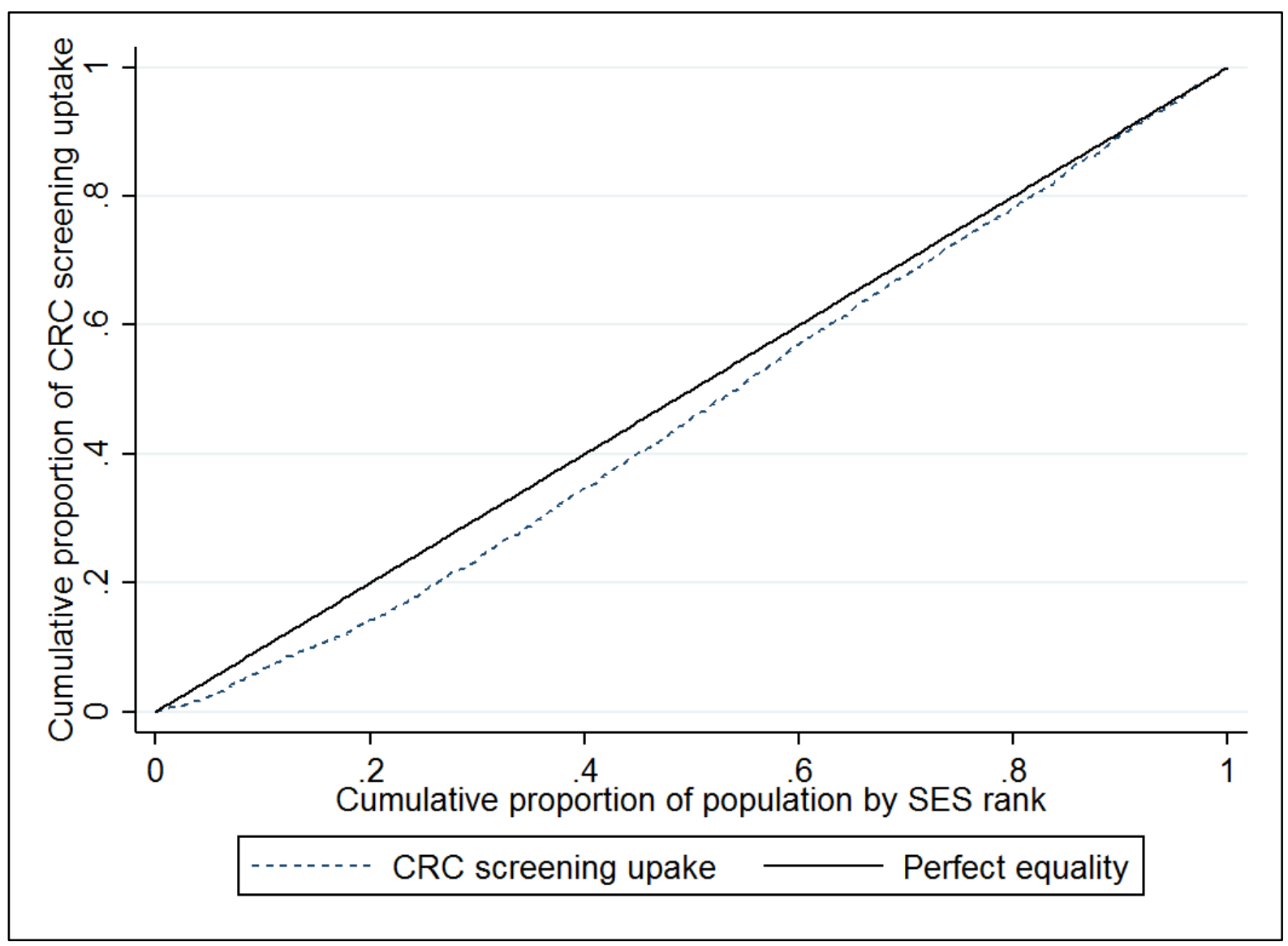


Table 1: Frequency of CRC screening uptake by socio-demographic, socio-economic and

\begin{tabular}{|c|c|c|c|}
\hline Socio-demographic & Screeni & ig uptake & \\
\hline variables & No, N(\%) & Yes, N(\%) & $P\left(x^{2}\right)$ \\
\hline Total $(\mathrm{N}=1,833)$ & $676(39.0)$ & $1,157(61.0)$ & \\
\hline Gender & & & \\
\hline Male & $345(55.4)$ & $484(45.1)$ & \\
\hline Female & $331(44.9)$ & $673(54.9)$ & 0.0001 \\
\hline Ethnicity & & & \\
\hline White & $650(95.1)$ & $1,135(97.5)$ & \\
\hline Non-White & $26(4.9)$ & $22(2.5)$ & 0.03 \\
\hline Education & & & \\
\hline No qualification & $176(29.8)$ & $207(20.5)$ & \\
\hline Other/foreign & $55(8.7)$ & $89(8.3)$ & \\
\hline Up to degree level & $309(43.8)$ & $606(51.8)$ & 0.0002 \\
\hline Degree or higher & $136(17.7)$ & $255(19.5)$ & \\
\hline Marital Status & & & \\
\hline Single (never married) & $45(6.6)$ & $51(3.9)$ & \\
\hline Married (once or more) & $469(70.7)$ & $877(77.5)$ & 7ח0 \\
\hline Separated/Divorced & $100(14.2)$ & $145(11.9)$ & 0.001 \\
\hline Widowed & $62(8.4)$ & $84(6.7)$ & \\
\hline Age & & & \\
\hline 61 & $89(14.9)$ & $129(11.9)$ & \\
\hline 62 & $96(15.1)$ & $167(15.1)$ & \\
\hline 63 & $94(13.0)$ & $129(11.0)$ & \\
\hline 64 & $87(11.8)$ & $178(14.4)$ & \\
\hline 65 & $75(10.8)$ & $120(10.3)$ & 0.5 \\
\hline 66 & $58(8.5)$ & $119(9.9)$ & \\
\hline 67 & $64(8.9)$ & $112(9.4)$ & \\
\hline 68 & $66(9.3)$ & $103(9.1)$ & \\
\hline 69 & $47(7.7)$ & $100(8.9)$ & \\
\hline
\end{tabular}

health-related

variables 
Table 1: (cont.)

\begin{tabular}{|c|c|c|c|}
\hline \multicolumn{4}{|l|}{ Socio-economic variables } \\
\hline \multicolumn{4}{|l|}{ Number of people in $\mathrm{HH}$} \\
\hline 1 & $158(21.6)$ & $213(16.7)$ & \multirow{4}{*}{0.0002} \\
\hline 2 & 399(58.2) & 796(68.9) & \\
\hline 3 or 4 & $106(18.0)$ & $139(13.6)$ & \\
\hline 5 or more & $13(2.2)$ & $9(0.8)$ & \\
\hline \multicolumn{4}{|l|}{ Occupational class } \\
\hline Unemployed/other & $7(1.6)$ & $4(0.6)$ & \multirow{6}{*}{0.01} \\
\hline Semi-routine/routine & 208(33.4) & $337(31.8)$ & \\
\hline Lower supervisor/technical & $67(11.2)$ & $97(9.2)$ & \\
\hline Small employer & $98(15.1)$ & $138(11.9)$ & \\
\hline Intermediate & $73(9.8)$ & 176(14.6) & \\
\hline Managerial & $223(28.9)$ & $405(31.9)$ & \\
\hline \multicolumn{4}{|l|}{ No. vehicles owned } \\
\hline 0 & $96(15.5)$ & $88(8.2)$ & \multirow{5}{*}{$<0.0001$} \\
\hline 1 & $328(47.9)$ & $551(47.4)$ & \\
\hline 2 & $190(27.6)$ & $411(35.1)$ & \\
\hline$>3$ & 62(9.3) & 107(9.3) & \\
\hline \multicolumn{3}{|l|}{ Housing Tenure } & \\
\hline Own it & $398(57.4)$ & $897(76.5)$ & \multirow{4}{*}{$<0.0001$} \\
\hline Mortgage & $140(19.5)$ & 153(12.9) & \\
\hline Rent & $127(21.4)$ & 102(10.1) & \\
\hline Other & $11(1.7)$ & $5(0.5)$ & \\
\hline \multicolumn{4}{|l|}{ Economic activity } \\
\hline Unemployed/other & $11(1.7)$ & $9(0.9)$ & \multirow{6}{*}{$<0.0001$} \\
\hline Retired/semi-retired & $374(54.5)$ & $753(64.8)$ & \\
\hline Employed & $149(22.1)$ & $257(22.3)$ & \\
\hline Self-employed & $62(9.0)$ & $63(5.5)$ & \\
\hline Sick/disabled & $48(8.4)$ & 19(2.0) & \\
\hline Looking after family & $32(4.3)$ & $56(4.5)$ & \\
\hline \multicolumn{4}{|l|}{$\begin{array}{l}\text { Quintiles net non-pension } \\
\text { wealth }\end{array}$} \\
\hline 1(Poorest) & $153(25.2)$ & $118(11.5)$ & \multirow{4}{*}{$<0.0001$} \\
\hline 2 & $121(17.7)$ & 199(17.5) & \\
\hline 3 & 116(17.2) & 242(21.1) & \\
\hline 4 & 132(19.0) & 289(24.3) & \\
\hline \multirow[t]{2}{*}{ 5(Richest) } & $154(20.9)$ & $309(25.5)$ & \\
\hline & $\begin{array}{r}\text { Mean } \\
\text { (SE) }\end{array}$ & $\begin{array}{r}\text { Mean } \\
\text { (SE) }\end{array}$ & $P(t)$ \\
\hline \multirow{2}{*}{$\begin{array}{l}\text { Net non-pension wealth } \\
\text { (wealth/1,000,000) } \\
\text { SES }\end{array}$} & $0.32(0.02)$ & $0.38(0.02)$ & 0.02 \\
\hline & $0.33(0.01)$ & $0.40(0.01)$ & $<0.0001$ \\
\hline
\end{tabular}


Table 1 (cont)

\begin{tabular}{|c|c|c|c|}
\hline Health variables & No, N(\%) & Yes, N(\%) & $P\left(x^{2}\right)$ \\
\hline \multicolumn{4}{|l|}{$\begin{array}{l}\text { Self-reported general } \\
\text { health }\end{array}$} \\
\hline Excellent & $72(9.9)$ & $169(14.4)$ & \multirow{5}{*}{$<0.0001$} \\
\hline Very good & $179(24.7)$ & $366(31.4)$ & \\
\hline Good & $244(36.4)$ & $399(34.3)$ & \\
\hline Fair & $132(21.0)$ & $171(14.8)$ & \\
\hline Poor & $49(8.0)$ & $52(5.1)$ & \\
\hline \multicolumn{4}{|l|}{$\begin{array}{l}\text { Long-standing limiting } \\
\text { illness }\end{array}$} \\
\hline No & $287(41.5)$ & $557(48.8)$ & \multirow{3}{*}{0.007} \\
\hline Yes, not limiting & $160(23.3)$ & $266(22.4)$ & \\
\hline Yes, limiting & $229(35.2)$ & $334(28.8)$ & \\
\hline \multicolumn{4}{|l|}{ Difficulty using the toilet } \\
\hline No & $656(97.1)$ & $1,134(97.9)$ & \multirow{2}{*}{0.34} \\
\hline Yes & $20(2.9)$ & $23(2.1)$ & \\
\hline \multicolumn{4}{|l|}{$\begin{array}{l}\text { Difficulty with daily living } \\
\text { activities }\end{array}$} \\
\hline No & $575(83.9)$ & $1,013(86.8)$ & \multirow{2}{*}{0.11} \\
\hline Yes & $101(16.1)$ & 144(13.2) & \\
\hline \multicolumn{4}{|l|}{ Partner who screened } \\
\hline No (no/ineligible) partner & $455(67.8)$ & $671(58.3)$ & \multirow{3}{*}{$<0.0001$} \\
\hline Partner not screened & $123(17.7)$ & $97(8.9)$ & \\
\hline Partner screened & $98(14.4)$ & $389(32.8)$ & \\
\hline \multicolumn{4}{|l|}{ Health literacy } \\
\hline Inadequate & $191(30.4)$ & $246(22.6)$ & \multirow{2}{*}{0.0008} \\
\hline Adequate & 485(69.6) & $911(77.4)$ & \\
\hline \multicolumn{4}{|l|}{ Geographical variable } \\
\hline \multicolumn{4}{|l|}{$\begin{array}{l}\text { Government Office } \\
\text { Region }\end{array}$} \\
\hline North East & $20(2.2)$ & $73(5.4)$ & \multirow{9}{*}{$<0.0001$} \\
\hline North West & $88(14.1)$ & $123(11.4)$ & \\
\hline Yorkshire \& The Humber & $57(8.0)$ & $136(12.1)$ & \\
\hline East Midlands & $67(8.8)$ & 134(10.0) & \\
\hline West Midlands & $74(10.7)$ & $142(12.5)$ & \\
\hline East of England & $77(10.5)$ & $167(13.1)$ & \\
\hline London & $77(14.0)$ & $78(8.7)$ & \\
\hline South East & 127(18.9) & $164(14.8)$ & \\
\hline South West & $89(12.8)$ & $140(12.0)$ & \\
\hline
\end{tabular}


Table 2: Results of univariate regressions

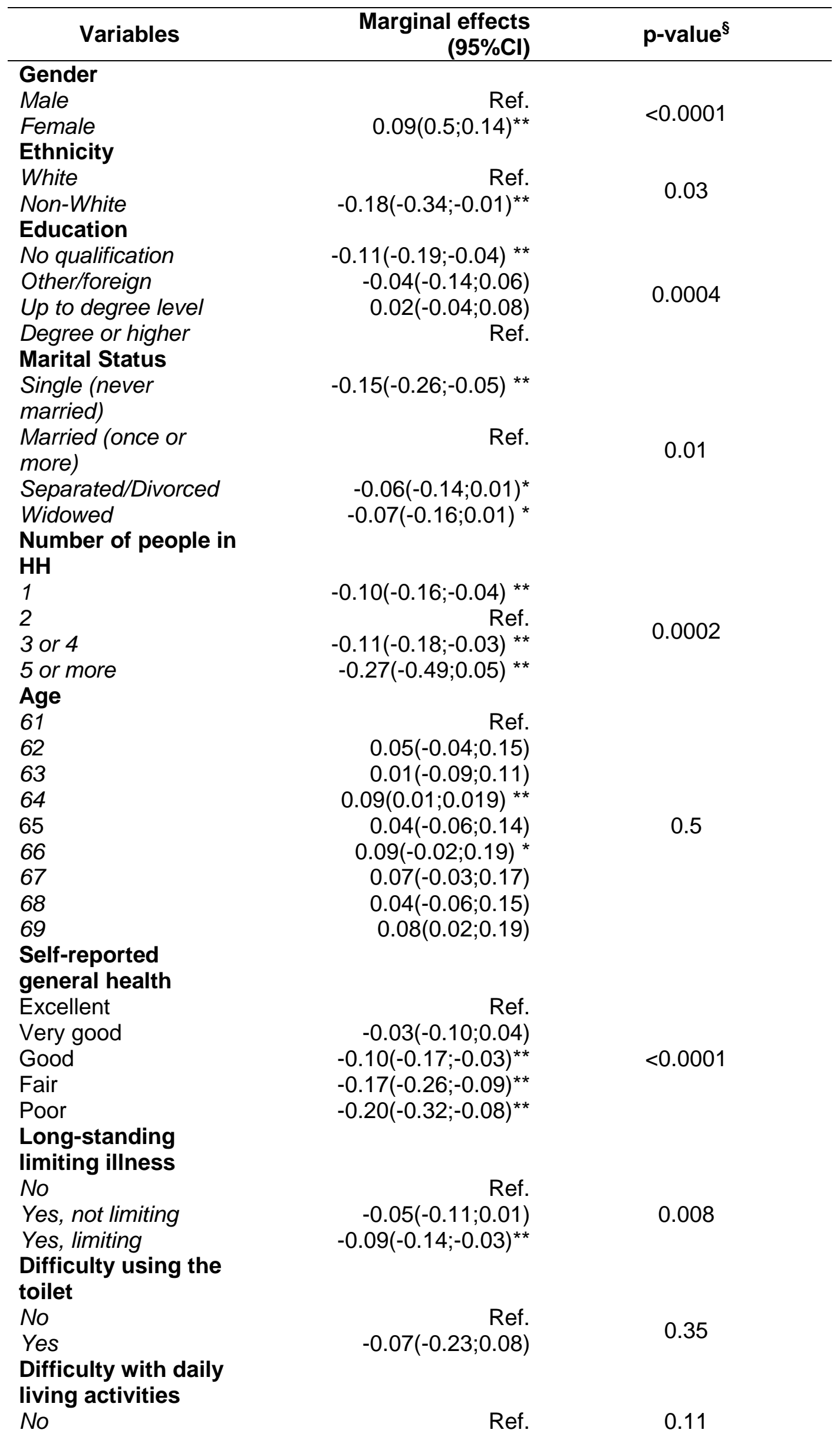


Table 2 (cont.):

\begin{tabular}{|c|c|c|}
\hline Variables & $\begin{array}{r}\text { Marginal effects } \\
(95 \% \mathrm{Cl})\end{array}$ & p-value ${ }^{\S}$ \\
\hline \multicolumn{3}{|l|}{ Health literacy } \\
\hline Limited & $-0.10(-0.15 ;-0.04)^{\star *}$ & \multirow{2}{*}{0.0008} \\
\hline Adequate & Ref. & \\
\hline \multicolumn{3}{|l|}{ Partner who screened } \\
\hline No (no/ineligible) partner & Ref. & \multirow{3}{*}{$<0.0001$} \\
\hline Partner not screened & $-0.13(-0.22 ;-0.05)^{\star *}$ & \\
\hline Partner screened & $0.21(0.15 ; 0.26)^{\star *}$ & \\
\hline \multicolumn{3}{|l|}{$\begin{array}{l}\text { Quintiles of net non- } \\
\text { pension wealth } \\
\text { (wealth/1,000,000) }\end{array}$} \\
\hline 1 (Poorest) & $-0.24(-0.32 ;-0.16)^{\star *}$ & \multirow{4}{*}{$<0.0001$} \\
\hline 2 & $-0.05(-0.12 ; 0.03)$ & \\
\hline 3 & $0.003(-0.07 ; 0.08)$ & \\
\hline 4 & $0.01(-0.06 ; 0.08)$ & \\
\hline 5(Richest) & Ref. & \\
\hline \multicolumn{3}{|l|}{ Occupational class } \\
\hline Unemployed/other & $-0.27(-0.57 ; 0.03)^{*}$ & \multirow{6}{*}{0.007} \\
\hline Semi-routine/routine & $-0.03(-0.09 ; 0.02)$ & \\
\hline Lower supervisor/technical & $-0.07(-0.16 ; 0.02)$ & \\
\hline Small employer & $\begin{array}{r}-0.08(-0.16 ;- \\
0.002)^{\star *}\end{array}$ & \\
\hline Intermediate & $0.07(-0.004 ; 0.14)^{*}$ & \\
\hline Managerial & Ref. & \\
\hline \multicolumn{3}{|l|}{ Vehicles } \\
\hline 0 & $-0.15(-0.26 ;-0.04)^{\star *}$ & \multirow{4}{*}{0.0001} \\
\hline 1 & $-0.001(-0.09 ; 0.09)$ & \\
\hline 2 & $0.06(-0.03 ; 0.15)$ & \\
\hline 3 or more & Ref. & \\
\hline \multicolumn{3}{|l|}{ Housing Tenure } \\
\hline Own it & Ref. & \multirow{5}{*}{$<0.0001$} \\
\hline Mortgage & $-0.17(-0.24 ;-0.10)$ & \\
\hline Rent & $-0.25(-0.32 ;-0.18)$ & \\
\hline Other & $-038(-064 \cdot-013)$ & \\
\hline CIIEI & $-0.00(-0.04,-0.101$ & \\
\hline \multicolumn{3}{|l|}{ Economic activity } \\
\hline Unemployed/other & $-0.17(-0.40 ; 0.06)$ & \multirow{7}{*}{$<0.0001$} \\
\hline Retired/semi-retired & $0.04(-0.02 ; 0.10)$ & \\
\hline Employed & Ref. & \\
\hline Self-employed & $-0.13(-0.23 ;-0.02)^{\star *}$ & \\
\hline Sick/disabled & $-0.34(-0.47 ;-0.22)^{\star *}$ & \\
\hline Looking after family & $-0.01(-0.11 ; 0.12)$ & \\
\hline Government Office Region & & \\
\hline North East & $0.25(0.14 ; 0.35)^{\star *}$ & \multirow{9}{*}{$<0.0001$} \\
\hline North West & $0.01(-0.09 ; 0.10)$ & \\
\hline Yorkshire \& The Humber & $0.15(0.06 ; 0.25)^{\star *}$ & \\
\hline East Midlands & $0.09(-0.01 ; 0.18)^{*}$ & \\
\hline West Midlands & $0.09(0.00 ; 0.19)^{\star *}$ & \\
\hline East of England & $0.11(0.02 ; 0.20)^{\star *}$ & \\
\hline London & $-0.06(-0.16 ; 0.05)$ & \\
\hline South East & Ref & \\
\hline South West & $0.04(-0.05 ; 0.14)$ & \\
\hline
\end{tabular}


**: $p \leq 0.05 ; *: 0.1>p>0.05$

$\S$ joint significance 
Table 3: Generalised linear regression model of net non-pension wealth/1,000,000 on socio-demographic/economic characteristics

\begin{tabular}{|c|c|c|}
\hline Variables & $\begin{array}{r}\text { Marginal effects } \\
(95 \% \mathrm{Cl}) \\
\end{array}$ & $\mathbf{Z}$ \\
\hline \multicolumn{3}{|l|}{ Gender } \\
\hline Male & Ref. & \\
\hline $\begin{array}{l}\text { Female } \\
\text { Aqe }\end{array}$ & $0.05(-0.01 ; 0.12)$ & 1.55 \\
\hline 62 & $0.02(-0.08 ; 0.13)$ & 0.36 \\
\hline 63 & $-0.02(-0.13 ; 0.08)$ & -0.44 \\
\hline 64 & $0.07(-0.05 ; 0.18)$ & 1.17 \\
\hline 65 & $0.04(-0.08 ; 0.16)$ & 0.73 \\
\hline 66 & $0.17(0.01 ; 0.32)$ & 2.12 \\
\hline 67 & $0.12(-0.03 ; 0.26)$ & 1.59 \\
\hline 68 & $0.12(-0.03 ; 0.26)$ & 1.60 \\
\hline 69 & $0.02(-0.11 ; 0.15)$ & 0.30 \\
\hline \multicolumn{3}{|l|}{ Education } \\
\hline No qualification & $-0.31(-0.42 ;-0.19)$ & -5.27 \\
\hline Other/foreign & $-0.23(-0.37 ;-0.09)$ & -3.28 \\
\hline Up to degree level & $-0.19(-0.30 ;-0.08)$ & -3.34 \\
\hline Degree or higher & Ref & \\
\hline \multicolumn{3}{|l|}{ Occupational Class } \\
\hline Unemployed/other & $-0.03(-0.47 ; 0.40)$ & -0.15 \\
\hline Semi-routine/routine & $-0.17(-0.25 ;-0.08)$ & -3.84 \\
\hline $\begin{array}{l}\text { Lower } \\
\text { supervis }\end{array}$ & $-0.13(-0.25 ;-0.02)$ & -2.30 \\
\hline Small employer & $-0.06(-0.18 ; 0.06)$ & -0.99 \\
\hline Intermediate & $-0.15(-0.25 ;-0.05)$ & -2.98 \\
\hline Managerial & Ref & \\
\hline \multicolumn{3}{|l|}{ No. Vehicles Owned } \\
\hline 0 & $-0.52(-0.72 ;-0.31)$ & -4.95 \\
\hline 1 & $-0.42(-0.62 ;-0.23)$ & -4.20 \\
\hline 2 & $-0.31(-0.51 ;-0.11)$ & -2.98 \\
\hline 3 or more & Ref & \\
\hline \multicolumn{3}{|l|}{ Housing Tenure } \\
\hline Own it & Ref & \\
\hline Mortgage & $-0.12(-0.19 ;-0.04)$ & -2.95 \\
\hline Rent & $-0.42(-0.46 ;-0.37)$ & -16.88 \\
\hline Other & $-0.36(-0.45 ;-0.27)$ & -7.89 \\
\hline \multicolumn{3}{|c|}{ Number of people in $\mathrm{HH}$} \\
\hline 1 & $-0.006(-0.09 ; 0.08)$ & -0.15 \\
\hline 2 & Ref. & \\
\hline 3 or 4 & $\begin{array}{r}-0.08(-0.16 ;- \\
0.001)\end{array}$ & -1.94 \\
\hline 5 or more & $\begin{array}{r}-0.16(-0.34 ;- \\
0.03)\end{array}$ & -1.65 \\
\hline \multicolumn{3}{|l|}{ Economic activity } \\
\hline Unemployed/other & $0.17(-0.21 ; 0.54)$ & 0.89 \\
\hline Retired/semi-retired & $0.03(-0.04 ; 0.11)$ & 0.91 \\
\hline Employed & Ref & \\
\hline Self-employed & $0.38(0.14 ; 0.62)$ & 3.06 \\
\hline Sick/disabled & $-0.08(-0.20 ; 0.04)$ & -1.25 \\
\hline Looking after family & $0.11(-0.06 ; 0.28)$ & 1.26 \\
\hline
\end{tabular}

Values in bold: $p \leq 0.05$ 


\begin{tabular}{|c|c|c|c|c|c|}
\hline Variables & $\begin{array}{c}\text { Multivariate } \\
\text { marginal } \\
\text { effects } \\
(95 \% \mathrm{Cl}) \\
\end{array}$ & Elasticity & $\mathrm{CCl}$ & Contr. & $\%$ Contr. \\
\hline \multicolumn{6}{|l|}{ Gender§ } \\
\hline Male & Ref. & Ref. & Ref. & Ref. & Ref. \\
\hline Female & $0.06(0.01 ; 0.11)^{\star *}$ & 0.04849 & -0.01828 & -0.00089 & -0.53105 \\
\hline \multicolumn{6}{|l|}{ Ethnicity } \\
\hline $\begin{array}{l}\text { White } \\
\text { Non white }\end{array}$ & $\begin{array}{r}\text { Ref. } \\
-0.004(-0.17 ; 0.15)\end{array}$ & $\begin{array}{r}\text { Ref. } \\
0.007445\end{array}$ & $\begin{array}{r}\text { Ref. } \\
0.018679 \\
\end{array}$ & $\begin{array}{r}\text { Ref. } \\
0.000139\end{array}$ & $\begin{array}{r}\text { Ref. } \\
0.083336 \\
\end{array}$ \\
\hline \multicolumn{6}{|l|}{ Educationa } \\
\hline No qualification & $-0.06(-0.14 ; 0.025)$ & -.02222 & -1.20465 & .02677 & $\begin{array}{r}16.04222 \\
2\end{array}$ \\
\hline Up to degree level & $-0.003(-0.10 ; 0.09)$ & -.000378 & -.57716 & .00021 & .13082 \\
\hline Other/foreign & $0.03(-0.03 ; 0.09)$ & .02441 & .16548 & .00403 & 2.42092 \\
\hline Degree or higher & Ref. & Ref. & Ref. & Ref. & Ref. \\
\hline Total & & & & 0.03101 & 18.59396 \\
\hline \multicolumn{6}{|l|}{ Marital Status } \\
\hline $\begin{array}{l}\text { Single (never } \\
\text { married) }\end{array}$ & $-0.04(-0.17 ; 0.08)$ & -.00354 & -.49304 & .00174 & 1.04834 \\
\hline $\begin{array}{l}\text { Married (once or } \\
\text { more) }\end{array}$ & Ref. & Ref. & Ref. & Ref. & Ref. \\
\hline Separated/Divorced & $0.01(-0.08 ; 0.01)$ & .00281 & -.667138 & -.00188 & -1.12668 \\
\hline Widowed & $-0.02(-0.12 ; 0.09)$ & -.00189 & -.54517 & .00103 & .61962 \\
\hline Total & & & & 0.00089 & 0.54128 \\
\hline \multicolumn{6}{|l|}{$\begin{array}{l}\text { Number of people in } \\
\mathrm{HH}\end{array}$} \\
\hline 1 & $0.01(-0.09 ; 0.10)$ & .00190 & -.67233 & -.00128 & -.76758 \\
\hline 2 & Ref. & Ref. & Ref. & Ref. & Ref. \\
\hline 3 or 4 & $-0.03(-0.09 ; 0.03)$ & -.00768 & -.15206 & .00116 & .70049 \\
\hline 5 or more & $\begin{array}{r}-0.21(- \\
0.42 ; 0.004)^{*}\end{array}$ & -.00456 & -.80150 & .00366 & 2.19458 \\
\hline Total & & & & 0.00354 & 2.12749 \\
\hline \multicolumn{6}{|l|}{ Age } \\
\hline 61 & Ref. & Ref. & Ref. & Ref. & Ref. \\
\hline 62 & $0.05(-0.04 ; 0.14)$ & 0.012287 & -0.17291 & -0.0021 & -1.27311 \\
\hline 63 & $-0.003(-0.09 ; 0.09)$ & -0.00061 & -0.19489 & 0.0001 & 0.07104 \\
\hline 64 & $0.08(0.00 ; 0.17)^{\star \star}$ & 0.018676 & -0.00662 & -0.0001 & -0.07406 \\
\hline 65 & $-0.001(-0.09 ; 0.09)$ & -.00029 & -.10025 & .00002 & .01766 \\
\hline 66 & $0.04(-0.05 ; 0.14)$ & .00674 & .42297 & .00285 & 1.71024 \\
\hline 67 & $0.003(-0.09 ; 0.09)$ & .00045 & .34611 & .00015 & .09346 \\
\hline 68 & $-0.01(-0.12 ; 0.09)$ & -.00220 & .29359 & -.00064 & -.38879 \\
\hline 69 & $0.05(-0.05 ; 0.15)$ & .00663 & -.29500 & -.00195 & -1.17345 \\
\hline Total & & & & -0.00167 & -1.01701 \\
\hline \multicolumn{6}{|l|}{$\begin{array}{l}\text { Self-reported } \\
\text { general health }\end{array}$} \\
\hline Excellent & Ref. & Ref. & Ref. & Ref. & Ref. \\
\hline \multirow{2}{*}{$\begin{array}{l}\text { Very good } \\
\text { Good }\end{array}$} & $-0.03(-0.11 ; 0.03)$ & -.01775 & .35720 & -.00634 & -3.80073 \\
\hline & $\begin{array}{r}-0.09(-0.17 ;- \\
0.03)^{\star \star}\end{array}$ & -.05573 & .07666 & -.00427 & -2.5609 \\
\hline Fair & $-0.09(-0.18 ; 0.00)^{*}$ & -.02598 & -.68095 & .01769 & 10.60237 \\
\hline Poor & $-0.05(-0.18 ; 0.07)$ & -.00571 & -1.10001 & .00628 & 3.76699 \\
\hline Total & & & & 0.01336 & 8.00773 \\
\hline
\end{tabular}


No

Yes, not limiting

Yes, limiting
Ref.

$-0.02(-0.07 ; 0.04)$

$0.02(-0.04 ; 0.08)$
Ref. $-.00587$ .01015
Ref.

15203 $-.46853$

Ref.

Ref. $-.53555$ $-2.85134$

$-.00475-2.85134$
$-0.00564$ 
Table 4 (cont)

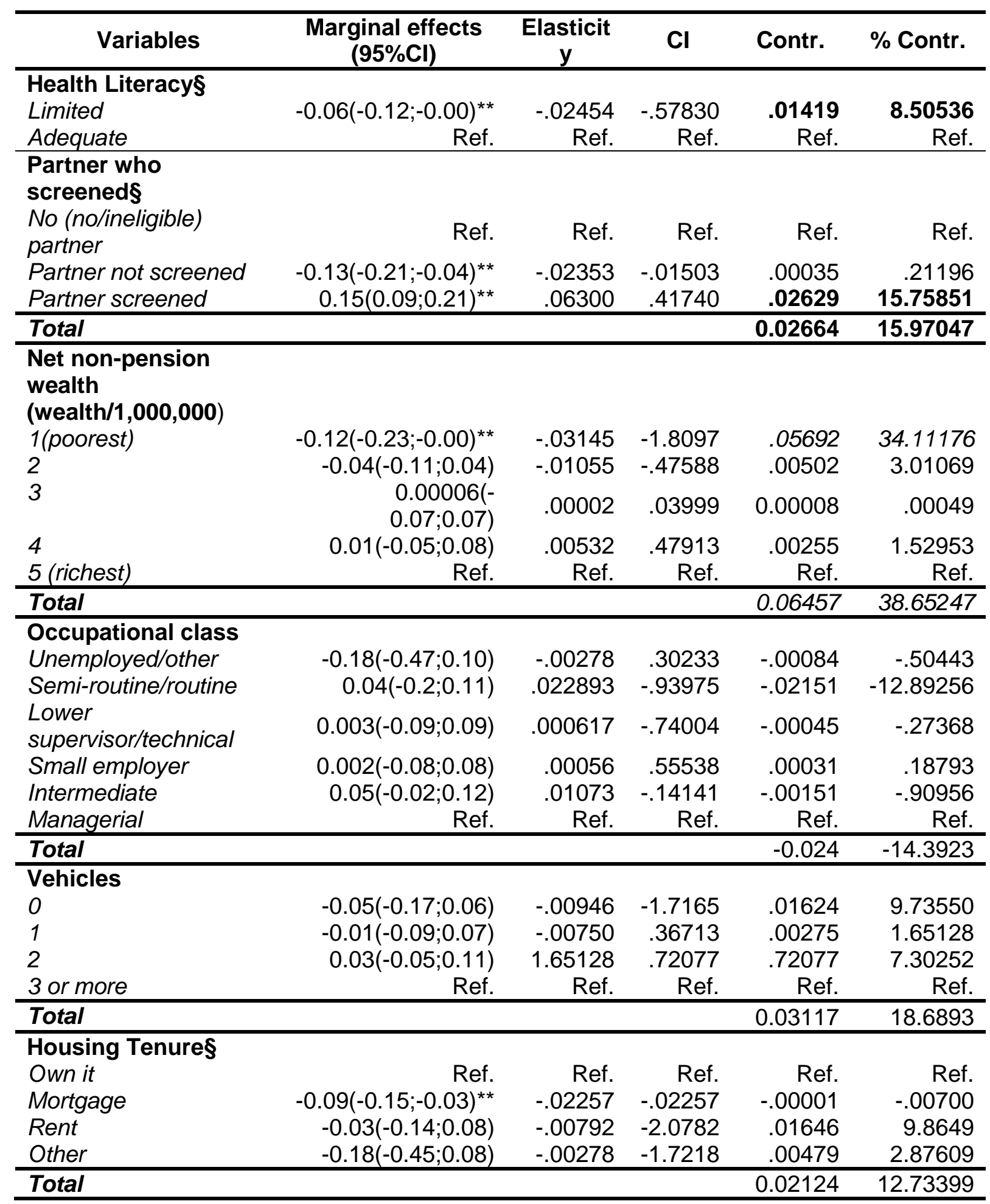


Table 4 (cont).

\begin{tabular}{|c|c|c|c|c|c|}
\hline \multicolumn{6}{|l|}{ Economic activity§ } \\
\hline Unemployed/other & $-0.13(-0.35 ; 0.09)$ & -.00236 & .43376 & -.00102 & -.61534 \\
\hline Retired/semi-retired & $0.04(-0.02 ; 0.09)$ & .03958 & -.03439 & -.00136 & -.81587 \\
\hline Employed & Ref. & Ref. & Ref. & Ref. & Ref. \\
\hline Self-employed & $-0.08(-0.19 ; 0.03)$ & -.00893 & $\begin{array}{r}1.7197 \\
3\end{array}$ & -.01536 & -9.21004 \\
\hline Sick/disabled & $-0.18(-0.33 ;-0.05)^{\star \star}$ & -.01299 & -1.7321 & .02251 & 13.49344 \\
\hline Looking after family & $-0.01(-0.13 ; 0.10)$ & -.00095 & -.00095 & -.00043 & -26050 \\
\hline Total & & & & 0.00434 & 2.59169 \\
\hline \multicolumn{6}{|l|}{$\begin{array}{l}\text { Government Office } \\
\text { Region }\end{array}$} \\
\hline North East & $0.28(0.19 ; 0.38)^{\star *}$ & .02063 & -.39926 & -.00823 & -4.93764 \\
\hline North West & $0.06(-0.02 ; 0.14)$ & .01215 & -.12691 & -.00154 & -.92458 \\
\hline $\begin{array}{l}\text { Yorkshire \& The } \\
\text { Humber }\end{array}$ & $0.16(0.07 ; 0.24)^{\star \star}$ & .02688 & -.33797 & -.00908 & -5.44433 \\
\hline East Midlands & $0.13(0.05 ; 0.21)^{\star *}$ & .01966 & -.03226 & -.00063 & -.38029 \\
\hline West Midlands & $0.15(0.07 ; 0.23)^{\star *}$ & .02868 & -.14942 & -.00428 & -2.56816 \\
\hline East of England & $(0.130 .05 ; 0.21)^{\star *}$ & .02485 & .23175 & .00575 & 3.45122 \\
\hline London & $0.04(-0.05 ; 0.13)$ & .00692 & -.13736 & -.00095 & -.57044 \\
\hline South East & Ref & Ref. & Ref. & Ref. & Ref. \\
\hline South West & $0.06(-0.02 ; 0.13)$ & .01120 & .32337 & .00362 & 2.17111 \\
\hline Total & & & & -0.01534 & -9.20311 \\
\hline Overall total & & & & 0.163553 & 97.96672 \\
\hline
\end{tabular}

Values in bold: $p \leq 0.05$; values in italics $0.1>p>0.05$ (contribution and $\%$ contribution in decomposition analyses)

${ }^{* *}: p<0.05 *: 0.1>p>0.05$

$\S: p<0.05 a: 0.1>p>0.05$ (joint significance - multivariate model)

${ }_{* * *}$ All variables with at least one value significant in univariate analyses were entered in the final multivariate one. 
